\title{
THE STRENGTH OF MATERIALS.
}

The Strength of Materials. By J. A. EwING, M.A., B.Sc., F.R.S., M.Inst.C.E. Professor of Mechanism and Applied Mechanics in the University of Cambridge, Fellow of King's College, Cambridge. Cambridge, The University Press, 1899. Pp. vii-xii + 1-246, with 150 illustrations in the text.

This work is intended to supply to students " in modern schools of Engineering" a "knowledge of the Strength of Materials and of its application in design $* * *$ which to be effective must be supplemented by laboratory and drawingoffice work." It is desirable that the mathematical elastician should learn what light modern experimental research throws on the validity of the hypotheses at the basis of the mathematical theory, and also that he should know what parts of his subject possess most interest for his more practical contemporaries. On the other hand, it is conceivable that the practical man may derive some advantage from realizing how the mathematical treatment which passes current in everyday life strikes the mathematician. This review thus naturally divides itself into two principal parts, the first dealing with the more experimental portions of the book, the second with the mathematical methods. A preliminary description of the contents of the book will facilitate comprehension.

After a brief preface and a table of contents, pp. vii-xii, chaps. I and II, pp. 1-23, define stress and strain, explain their simpler common types, and treat of the ordinary moduli, or elastic constants, for isotropic material. Chap. III, pp. 24-58, treats of ultimate strength and non-elastic strain, dealing mainly with simple tension and compression, describes the phenomena presented during the loading of steel and iron up to rupture, and discusses experiments on the effects of rest or of heating after over-straining. It also gives an account of Wohler's experiments on the "weakening " of material under very frequent repetitions of loading and unloading. Chap. IV, pp. 59-95, describes-with excellent illustrations-a number of testing machines and instruments for measuring extensions and compressions, discusses some methods of determining the modulus of rigidity and gives some numerical results.

Chaps. V, VI, and VII, pp. 96-153, deal mainly with the application of the ordinary Bernoulli-Euler mathematical 
theory to beams. Analytical methods are generally followed, but the ordinary graphic methods are also illustrated. Chap. VIII, pp. 154-170, treating of "frames," may be regarded as part of a text book on ordinary statics. Chap. IX, pp. 171-186, treats of struts and columns, first on Euler's mathematical theory, and then from the more empirical standpoint of Gordon or Rankine's formula. Chap. X, pp. 187-203, is denominated "Torsion of Shafts." It is however not confined to this, but touches upon the theory of spiral springs and the "whirling" of rotating shafts. Chap. XI, pp. 204-217, treats of shells and thick cylinders under pressure, with a discussion of rotating rings and thin discs. Chap. XII, pp. 218-237, is devoted to "Hanging Chains and Arched Ribs," including parabolic chains, the common catenary, etc. An appendix, pp. 239242 , gives numerical data as to strengths and densities of ordinary building materials ; and an index occupies pp. 243246.

Experiment.-The fundamental fact underlying the ordinary mathematical theory, and therefore all ordinary girder theory, whether its outward form be graphical or analytical, is Hooke's law that stress is proportional to strain, or-as Professor Pearson puts it-that the stress-strain relation is linear. On this point we are told (Art. 15) "A material is elastic $* * *$ if the strain disappears when the stress is removed. Strain which persists after the stress $* * *$ is removed is called permanent set. *** Actual materials are in general nearly perfectly elastic with regard to small stresses $* * *$ if the applied stress is less than a certain limit, the strain $* * *$ disappears wholly or almost wholly when the stress is removed. $* * *$ The limits of stress within which strain is wholly or almost wholly elastic are called limits of elasticity $* * *$. (Art. 16) Within the limits of elasticity the strain $* * *$ is proportional to the stress." Later we have the following statement (Art. 32): "Within these limits (of elasticity) we may without seriousinaccuracy take the strain as $* * *$ proportional to the stress and as disappearing when the stress is removed. Strictly speaking, absolute proportionality of strain to stress is never found, and probably there is no stress, however small, that does not produce some permanent effect. There is always some slight hysteresis or lagging in the relation of strain to stress. *** Butin general this imperfection of elasticity is so slight that $* * *$ up to a certain limit, which is in general pretty well defined, Hooke's Law may be taken as substantially accurate." 
A student when reading Art. 15 would be apt to conclude that the only two things known to exist are elastic strain disappearing simultaneously with the removal of the stress, and set persisting permanently. In Act. 32 he seems, however, expected to distinguish between set and hysteresis (a term which seems equivalent to " Elastische Nachwirkung", or what Pearson calls "Elastic after-strain"). It is to be regretted that the author does not bring out more clearly the theoretical distinction between set which persists and strain which gradually disappears, especially as the practical discrimination between them is so difficult.

Another question is whether the author is well advised in assuming-as he seems tacitly to do-that failure of Hooke's law necessarily implies the existence of hysteresis, or set, and conversely. It is at least conceivable that materials exist in which the relation between stress and elastic strain is not linear. Experiments by Hodgkinson, Kupffer, and others have sometimes been supposed to show that cast iron is such a material. Our author refers to Hodgkinson's experiments (Art. 38), but not in such a way as to show whether he is aware of the interpretation put upon them by others (see Todhunter and Pearson's "History of Elasticity" Vol. 1, Note D, p. 891 ; Vol. 2, Art. 793, etc.). The subject seems one which might repay experimental re-investigation with modern appliances.

The next question that calls for consideration is that which gives its name to the book. In Art. 33 we are told "The load which suffices to cause rupture measures the ultimate strength of the piece." At this stage, however, a difficulty comes in. Engineering calculations are almost all ultimately based on Hooke's law. But when the stress is carried beyond the elastic limit the departure from the law begins to be serious, and with the approach of rupture the law is often a travesty of the facts. If then calculation supplies values for the stresses or strains, at any point of a structure, such as answer to the breaking load, the only legitimate conclusion is that the physical basis for the calculation is not satisfactory. It would certainly be prudent in such a case to conclude that the load contemplated is excessive, or badly distributed; but how excessive it may be, or what would happen if it were applied, lies outside the range of the ordinary theory. From the theoretical standpoint the most logical course would seem to be to consider not the breaking load but that answering to the elastic limit. According to our author, the elastic limit is usually pretty clearly defined in most building materials ; and, supposing 
this to be true, there would not appear to be serious objection on the practical side to focussing attention on it rather than on the breaking load. It appears, however, to be the invariable or almost invariable custom amongst practical men to make use ostensibly of the breaking load modified by so-called "factors of safety." After giving the definition

$$
\text { factor of safety }=\left(\begin{array}{c}
\text { ultimate strength }) \div(\text { extreme working } \\
\text { stress }),
\end{array}\right.
$$

our author adds (Art. 34): "The rational use of a factor of safety $* * *$ results $* * *$ in preventing waste of material locally by making the margin of strength equal for all parts." Perhaps a more logical way of presenting the facts would be to say that what the engineer puts before him is the "extreme working stress" which he gets by dividing his ultimate strength, $i$. e., breaking load, by a certain number which he calls a factor of safety. Supposing the working stress thus arrived at not to strain the material beyond the elastic limit, there is no objection on mathematical grounds to calculations in which it plays a part.

There still, however, remains a difficulty ; for how are we to determine the factor of safety? On this point we are told in Art. 34: "The choice of a factor $* * *$ depends on many considerations, such as the probable accuracy of the estimated loads and also that of the theory $* * *$ the possible effects of bad workmanship, $* * *$ the variability or uniformity of the load. $* * *$ The factor $* * *$ also serves to provide for $* * *$ incidental shocks. $* * *$ The factor $* * *$ is rarely less than 3 , it is very commonly 4 or 5 , and it is sometimes as much (in machines) as 10 or 12." The factor of safety covers, in short, uncertainty in the material, unforeseen contingencies from loading or weather, and gaps in the engineer's physical or mathematical knowledge. So long as all these sources of uncertainty are lumped together, "a rational use of a factor of safety" seems rather much to hope for. One of the things most likely to narrow the range of uncertainties is a knowledge of what really determines the changes that take place in the material as the load is raised. There are various theories bearing on this point. The three principal believe that in isotropic materials the crux is: (1) the maximum principal stress, (2) the maximum stress-difference (or difference between the greatest and least principal stresses), (3) the greatest principal strain. Of these theories the first-employed by Lamé and others-is now hardly supported by any the- 
oretical elastician; the second-suggested by Tresca's experiments on the flow of metals-has been used by Prof. G. H. Darwin and others; the third was that advocated by St. Venant. Our author refers explicitly to no theory. In dealing with ultimate strengths he invariably speaks of the stress, and his language in many places (e. g., Art. 8 where he says "the greatest principal stress measures the greatest intensity which the material has to bear") certainly suggests that he supports the first or greatest stress theory of rupture. In general, however, he really avoids committing himself. When a piece of given material, of given size and shape, is loaded in a particular way, so long as Hooke's law holds, doubling the load doubles alike every stress and strain ; thus the condition of the material can be defined by specifying the magnitude of any one convenient stress or strain. In such a case the laying down a limiting stress does not commit one to any theory of rupture. If, for instance, we take a uniform bar under simple tension $S$, the greatest stress and the maximum stress-difference are both $S$, and the greatest strain is $S / E$, where $E$ is a constant for the material (Young's modulus). Thus we may specify that the working stress shall not exceed $\bar{S}$, and yet believe that the critical thing is that the maximum stress-difference shall not exceed $\bar{S}$, or the greatest strain shall not exceed $\bar{S} / E$. Our author refers to separate limiting stresses for simple tension, simple compression, and shearing; and if the simple states were those that always existed, one might get along fairly comfortably without any theory of rupture. As matters actually stand, however, empiricism is under the disadvantage that absolutely simple tension, compression, or shearing are rather ideal states, and are only approximated to even in the testing machine. In some of the problems treated in this book the stress system is not simple, and, as we shall see later, the conclusions drawn as to the strength are not always reliable unless the maximum stress theory be really true.

Nature of material.-In Arts. 17 to 19, Young's and the rigidity moduli are defined in a way applicable only to isotropic materials, while isotropy is first mentioned, and then only incidentally, in Art. 20. In Art. 26, where the stressstrain relations are formulated, it is indeed mentioned that isotropy is assumed, but nothing is said as to the general form of the relations in non-isotropic materials. In Art. 33 there are fuller references to differences between isotropic and non-isotropic materials, but only from the point of view 
of ultimate strength. The same article tells us that wrought iron is not isotropic, and data confirming this statement appear in Table III, p. 241. Yet in Table IV, p. 241, there appear values of Young's and the rigidity moduli for wrought iron, as if it were isotropic, and we even have a Young's modulus given for "timber" without any specification of direction. All the mathematical calculations in the book, which depend in any way on the precise form of the stress-strain relations, tacitly assume isotropy ; and no attempt is made to ascertain what modification is necessary to render the results applicable to non-isotropic material. This assumption of isotropy is by no ineans peculiar to the present work. Rankine and St. Venant indeed in various writings intended for practical men treated nonisotropy in considerable detail, but we know of no recent English practical writer who has followed this example. It is very possibly undesirable that elementary books should go into much detail in this matter, but greater prominence should be given to the limitations involved by the assumption of isotropy, whose occurrence is after all probably the exception rather than the rule.

Mathematical treatment. - The author puts stresses in the forefront. Supposing the three principal stress directions to coincide with the rectangular axes, then the strain " $e_{x}$ is made up partly of the direct strain which (the stress) $p_{x}$ produces in its own direction, and partly of the lateral strains produced by $p$ and $p_{z}$ "' (p. 21). In this way Young's modulus and Poisson's ratio at once come to the front as elastic constants. The general properties of strain, the relations of strain to displacement, the surface stress equations and the ordinary body stress differential equations are not considered. When the basis provided proves too narrow, as it sometimes does-e. g., in Arts. 143 and 147-, the author makes such supplementary assumptions as he finds necessary. This seems a trifle hard on the conscientious student whose knowledge of elasticity is confined to this book. The proof of the " equality of shearing stress in two directions" in Art. 12 is not rigid; the author makes no use of his hypothesis that the cube is indefinitely small, and in fact does not refer at all to bodily forces. The use of $1 / \sigma$ for Poisson's ratio may lead to confusion, as that quantity is represented by $\sigma$ in Thomson and Tait's Natural Philosophy and in Love's Treatise on Elasticity. Again in Art. 147, $1 / \sigma$ is replaced by $\mu$ - used to represent the rigidity by St. Venant, Pearson, Love, etc. - the rigidity itself being denoted by $C$. In discussing the 
determination of the rigidity in Article 72, $\mu$ is used for the twisting couple for unit angle of twist. The difference between static and kinetic moduli is presumably an unnecessary refinement in engineering, so that the absence of reference to the subject in Arts. 71 and 72 is hardly surprising, but in Art. 73 the discussion of Maxwell's method of determining the rigidity might well have called attention to the fact that it keeps the tension of the wire unaltered and eliminates the moments of inertia of the shifted masses round their own axes of figure.

Before entering on a discussion of beam problems in Chap. V, the author describes " uniformly distributed stress," which means stress the same in intensity and direction at every point of a plane surface, and "uniformly varying stress" in which the stresses are parallel, but vary as the distance from some line (a "neutral axis") in the plane to which they are perpendicular. He adds (Art. 79) : " Uniformly varying stress is practically important because it occurs $* * *$ in a bent beam, in a tie-rod when subjected to a non-axial pull, and in a long strut or column." In short the author assumes the ordinary Bernoulli-Euler theory for beams whether locally or generally loaded. He considers first the stresses alone, explaining several graphic methods. He then proceeds to determine the "slopes" and "deflections" in beams, on the assumption that "The strain on any imaginary filament taken along the length of the beam is sensibly the same as if that filament were directly compressed or extended by itself" (Art 97). Supposing $x$ measured parallel to the length of the beam, and denoting the slope by $i$, the deflection by $u$, and the radius of curvature of the central axis by $R$, the author (Art. 99) deduces $1 / R=d i / d x=d^{2} u / d x^{2}$, whence $i=\int(1 / R) d x$, $u=\int i d x$. Having expressed $1 / R$ in terms of the bending couple by the Bernoulli-Euler method, he thus arrives by one step at $i$ and by a second step at $u$. In introducing the formula $1 / R=d^{2} u / d x^{2}$ the author specifies that the deflection is assumed very small, but he does not explain that this means that $(d u / d x)^{2}$ is neglected as compared to unity.

The strained form of a bent beam is illustrated by Fig. 84, Art. 102. This would have been clearer if the excess of width at the top had been more exaggerated (cf. Thomson and Tait's Natural Philosophy, Art. 716). Also when the author says: "The lateral strain being $1 / \sigma$ of the longitudinal strain, the anticlastic or transverse curvature * * * is $1 / \sigma$ of the longitudinal," one cannot but fear that 
the student will obtain an erroneous idea both of what is meant by "anticlastic curvature" and of what actually takes place. The conclusions in the end of Art. 102 as to the bending of a "wide flat strip" seem hardly in accordance with Pearson and Filon's results (Quarterly Journal of Pure and Applied Mathematics, Vol. 31, p. 66, especially Arts. 52 et seq.). The author's treatment of the ordinary first approximation results for beams has much to commend it, especially for students weak at mathematical analysis. When, however, he tries to improve on the first approximation results, he is less satisfactory. Thus in Art. 95 when deducing the distribution of shearing stress over the section of a beam, and in Art. 105, when applying the results so obtained to the calculation of the "additional deflection due to shearing," he tacitly assumes that the shearing stress is the same at every point of a narrow strip perpendicular to the plane of bending. We are not aware that this has been proved in any particular case ; it is not in accordance with the solution obtained by St. Venant for beams under terminal shearing force (Todhunter and Pearson's History, Vol. 2, Part I, p. 64), or with that found by Pearson and Filon for a heavy elliptic beam (1. c., pp. 88 and 98). Further the " correction"' in A rt. 105 is of the same order of magnitude as the difference between the vertical displacements at different points of the cross section ; it was obtained by equating work done by stresses to work done by gravity on the load, while no account was taken of what part of the central section the load was applied at.

In dealing with such matters, a reviewer cannot but regret the great scarcity of references in the work to mathematical text books or papers. There are two or three references to Lord Kelvin and one to Pearson, in connection with experimental work or definitions, while St. Venant is mentioned generally in connection with torsion; but to the text books of these authors, or to that of Love, or to their mathematical papers, there seems no reference anywhere. Thus when the author reaches an unusual result one is uncertain whether it has or has not any more substantial basis than the proof presented in the book. The average engineering student is perhaps unlikely to utilize references, but their presence would at least not harm him and should facilitate enlargement of ideas amongst the more competent.

The treatment of "frames" in Chap. VIII is condensed, and various assumptions,-e. g., in Arts. 113, 116, 117, and 
119-seem to require more explanation. The index tells us that the " method of reciprocal figures" in Arts. 114 et seq. is due to Maxwell, but his name does not appear in the text. The subject of "redundant members" in frames is very lightly touched upon, and there is no reference to Macaulay's recent extension of Maxwell's method (Philosophical Magazine, Jan., 1898, p. 42).

The treatment of struts in Chap. IX is fairly full, but the explanation of Euler's method in Art. 122 might be improved. On p. 172 the curvature is taken as $d^{2} u / d y^{2}$ without restriction. The solution of course assumes that $(d u / d y)^{2}$ is negligible, and yet the conclusion is drawn : "the same force will serve to keep the strut bent whether the curvature is small or not so small." Presumably in engineering practice anything but small curvature is rare, but considerable elastic bending is easily introduced in thin rods, and a reference to some more general treatment (e. g., Love's Elasticity, Vol. 2, Arts. 227 et seq.) would appear desirable. The conclusion reached by the author (Art. 122) that the length of a segment of a bent strut may be any submultiple, even or odd, of the whole length, is correct, but it does not follow from his mathematics. His final equation justifies his conclusion $(P / E I)^{1 / 2}(L / 2)=n \pi / 2$, only when $n$ is an odd integer. The fact is that in originally assuming $u=u_{1} \cos \left\{(P / E I)^{1 / 2} y\right\}$ the author excluded all cases in which the displacement $u$ vanishes at the center of the rod (his origin). The illustration selected in Art. 126 of "struts with lateral load" is rather curious. A bending moment whose true value is $(W L / 8)\left\{1-(2 x / L)^{2}\right\}$ is represented as $(W L / 8) \cos (\pi x / L)$, thus replacing the true differential equation by one of the type

$$
\left(d^{2} u / d x^{2}\right)+a u+c \cos b x=0 .
$$

A pure mathematician, it may be feared, would hardly accept as adequate the explanations that "a parabola $* * *$ is not far from coincidence with a curve of sines" and that $1-(2 x / L)^{2}$ agrees in value with $\cos (\pi x / L)$ both when $x=0$ and when $x=L / 2$. It may be added-as a personal contribution from the reviewer-that while the solution of the true differential equation presents no real difficulty, the result does not lend itself to manipulation by quite elementary methods.

Chap. X calls for a few criticisms. Art. 127 assumes-as is indeed usual-that when a circular shaft of any length is twisted in any symmetrical way each element suffers a 
displacement directly proportional to its distance from the axis. There are in reality any number of possible symmetrical kinds of twisting, the species depending on the force system applied, and unless the length be great compared to the diameter there is no a priori reason to suppose that the stress and strain will even approximate to the ordinary simple law (see Cambridge Transactions, vol. 14, p. 365). The crank shaft dealt with in Art. 131 is a case where the application of the Bernoulli-Euler method is somewhat speculative. The author seems here to hesitate between the greatest principal stress and the maximum shearing stress as the criterion for rupture, but his language is rather ambiguous. In Art. 133, dealing with torsion beyond the elastic limit, the author supposes that the twisting couple can be increased until practically the whole of the material--starting with the outer layers-passes beyond the elastic limit, and that the altered material possesses everywhere the same shearing stress $q^{\prime}$; he speaks of $q^{\prime}$ as " the ultimate shearing stress of the material." In Arts. 84 and 85 the author presented a closely similar view in dealing with the bending of rectangular beams; stating that the stress may approach a limiting condition in which there is a uniform longitudinal tension over one half the cross section and an equal compression over the other half. It would be desirable that the conditions should be clearly stated under which material may be expected to behave in the way assumed in these articles, and that there should be references to experiments on the subject. The point seems of importance in connection with theories of rupture. In Arts. 134 and 135 dealing with spiral springs a reference to some more complete treatment of the subject would be particularly desirable. When the author (p. 197) talks of resolving "angles about the axes $o x$ and $o y$ to find the horizontal and vertical components of the angular displacement $* * *$ ' his meaning may be plain to the practical man, but it certainly is not so to one habituated to a different usage of mathematical terms. Art. 138 dealing with the whirling of shafts is more satisfactory, but it might be desirable to tell the student that the formala $d^{2} M / d x^{2}=4 \pi^{2} n^{2} w u / g$, which is really assumed in the proof, is obtainable by ordinary statics. It would also be well to refer to the possibility that the material may be strained beyond the elastic limit before "whirling", can come in (Proceedings of the Cambridge Philosophical Society, vol. 7, p. 283).

Chapter XI deals with several interesting problems, but the author is handicapped, as in Chapter $\mathrm{X}$, by his avoid- 
ance of the less elementary methods. The assumption that "hoop stresses" are the same at every point of the thickness of a thin shell-whether spherical, or cylindrical (of circular or elliptical section) - is a short way of reaching results, but it has the serious disadvantage of possessing limitations on which it throws no light. In the "oval section," Article 142, the hypothesis seems of doubtful validity under any conditions (cf. Todhunter and Pearson's History, Vol. 2, Part 1, Arts. 537-538). Articles 143-4 treating of the thick circular cylinder are less elementary and more satisfactory ; but the author has to introduce the supplementary assumption that the longitudinal strain is uniform, and he commits himself to the greatest stress theory of rupture. As this is a specially good example of the difficulty of getting along without some general theory of rupture, and also of the expediency of knowing what the true theory is, the reviewer ventures on a slight addition to the text. The displacements $u$ along the radius from the cylindrical axis, and $w$ parallel to its length taken as the $z$-axis, are of the type (Proceedings of the Cambridge Philosophical Society, Vol. 7, p. 204)

$$
u=\alpha r+D / r, \quad w=A z,
$$

where $A, \alpha, D$ are constants determined from the surface conditions. Suppose these conditions to be uniform pressures $p_{i}$ and $p_{e}$ over the inner and outer cylindrical surfaces, whose radii are $r_{1}$ and $r_{2}$, along with uniform tension $P$ parallel to the cylindrical axis (we may suppose $P$ to represent the action of closed ends when such exists). Then denoting Young's modulus by $E$ and Poisson's ratio by $\eta$, we easily find

$$
\begin{aligned}
& u=r\left\{\frac{1-\eta}{E} \frac{r_{1}^{2} p_{i}-r_{2}^{2} p_{e}}{r_{2}{ }^{2}-r_{1}^{2}}-\eta \frac{P}{E}\right\}+\frac{1+\eta}{E} \frac{r_{1}{ }^{2} r_{2}{ }^{2}}{r} \frac{p_{i}-p_{e}}{r_{2}{ }^{2}-r_{1}{ }^{2}} ; \\
& w=z\left\{\frac{P}{E}-\frac{2 \eta}{E} \frac{r_{1}^{2} p_{i}-r_{2}{ }^{2} p_{e}}{r_{2}{ }^{2}-r_{1}^{2}}\right\} .
\end{aligned}
$$

Art. 143 treats the case when $P$ and $p_{e}$ vanish, for which

$$
\begin{gathered}
u=\frac{p_{i}}{E} \frac{r_{1}{ }^{2}}{r_{2}^{2}-r_{1}^{2}}\left\{(1-\eta) r+(1+\eta) r_{2}^{2} / r\right\} ; \\
w=-\frac{2 \eta p_{i}}{E} \frac{r_{1}^{2} z}{r_{2}^{2}-r_{1}^{2}} .
\end{gathered}
$$


The corresponding principal stresses, in Todhunter and Pearson's notation (the radial, the "hoop," and the longitudinal) are

$$
\begin{gathered}
\widehat{r r}=-p_{i}\left(r_{1} / r\right)^{2}\left(r_{2}{ }^{2}-r^{2}\right) /\left(r_{2}{ }^{2}-r_{1}^{2}\right) ; \\
\widehat{\varphi \varphi}=p_{i} r_{1}^{2}\left(1+r_{2}{ }^{2} / r^{2}\right) /\left(r_{2}{ }^{2}-r_{1}{ }^{2}\right) ; \overparen{z z}=0 .
\end{gathered}
$$

Everywhere $\overparen{\varphi \varphi}$ is the greatest stress, $\overparen{\varphi \varphi}-\overparen{r r}$ the maximum stress-difference, and $u / r$ the greatest strain ; and all three quantities have their greatest values over the inner cylindrical surface, where

$$
\begin{gathered}
\overparen{\varphi \varphi}=p_{i}\left(r_{1}^{2}+r_{2}^{2}\right) /\left(r_{2}^{2}-r_{1}^{2}\right) ; \widehat{\varphi \varphi}-\overparen{r r}=2 p_{i} r_{2}^{2} /\left(r_{2}^{2}-r_{1}^{2}\right) ; \\
u / r=\left(p_{i} / E\right)\left\{r_{2}^{2}+r_{1}^{2}+\eta\left(r_{2}^{2}-r_{1}^{2}\right)\right\} /\left(r_{2}^{2}-r_{1}^{2}\right) .
\end{gathered}
$$

Now suppose, as in Art. 143, that $f$ is the largest safe tension in a long bar of the material ; then $f$ is a superior limit : on the greatest stress theory to $\overparen{\varphi \varphi}$, on the maximum stress difference theory to $\widehat{\varphi \varphi}-\overparen{r r}$, and on the greatest strain theory to $E(u / r)$. Thus if the limiting values allowed by the three theories to the internal pressure be respectively $p_{i}^{\prime}, p_{i}^{\prime \prime}$ and $p_{i}^{\prime \prime \prime}$, we have

$$
\begin{gathered}
p_{i}^{\prime}=f\left(r_{2}^{2}-r_{1}^{2}\right) /\left(r_{2}^{2}+r_{1}^{2}\right) ; p_{i}^{\prime \prime}=f\left({r_{2}}^{2}-r_{1}^{2}\right) /\left(2{r_{2}}^{2}\right) ; \\
p_{i}^{\prime \prime \prime}=f\left(r_{2}{ }^{2}-r_{1}^{2}\right) /\left\{r_{2}{ }^{2}+r_{1}{ }^{2}+\eta\left(r_{2}{ }^{2}-r_{1}^{2}\right)\right\} ;
\end{gathered}
$$

and so

$$
p_{i}^{\prime \prime}=p_{i}^{\prime}\left(r_{2}^{2}+r_{1}^{2}\right) /\left(2 r_{2}^{2}\right) ;
$$

$$
p_{i}^{\prime \prime \prime}=p_{i}^{\prime} \div\left\{1+\eta\left(r_{2}^{2}-r_{1}\right) /\left(r_{2}^{2}+r_{1}^{2}\right)\right\} \text {. }
$$

As $r_{2}^{2}>r_{1}^{2}$, clearly $p_{i}^{\prime}$ is always larger than $p_{i}^{\prime \prime}$ or $p_{i}^{\prime \prime \prime}$; or the greatest stress theory-of which alone our author takes cognizance-allows a greater internal pressure than either of the other two theories would consider safe. In a very thin shell $p_{i}^{\prime}, p_{i}^{\prime \prime}$, and $p_{i}^{\prime \prime \prime}$ approach equality ; but in a very thick shell we have ultimately $p_{i}^{\prime \prime}=p_{i}^{\prime} / 2, p_{i}^{\prime \prime \prime}=p_{i}^{\prime} /(1+\eta)$.

"The use of initial internal stress in strengthening a thick tube" (Art. 145) represents a case where a good deal may depend on the theory of rupture adopted. Art. 146 assumes the stress in a revolving ring to be uniform over the cross section. Presumably this is approximately true when the diameter of the cross section is small compared to the aper- 
ture of the ring, but not otherwise, and the conclusions arrived at should be correspondingly restricted.

Art. 147 dealing with the "stress in a revolving disc" is perhaps the nearest approach in the book to the use of the strict mathematical theory. In drawing conclusions as to the fastest safe speed of rotation the author again confines himself to the greatest stress theory. It happens, however, that all three rupture theories mentioned above allow the same limiting velocity in the case of a dise with a hole. In the disc without a hole the greatest stress and maximum stress difference theories likewise agree, but the greatest strain theory allows a velocity greater than that allowed by the other two theories in the ratio $1: \sqrt{1-\eta}$. The problem of the rotating disc has had a somewhat curious history, an account of which-with a more complete treatment of the problem-will be found in the Proceedings of the Cambridge Philosophical Society, Vol. 7, p. 201.

Units.-Those who regard the retention of British units as a sign post on the road to destruction will regard the author as situated far on the downward track. There seems no reference to the C. G. S. system except in footnotes on pp. 3 and 53, which give the relation between tons or lbs. per square inch and kilogrammes per sq. $\mathrm{cm}$. The tables of strength and of elastic moduli at the end use "tons per sq. inch," whilst the table of the "approximate weights of materials" uses "lbs. per cubic foot." In Art. 130 work is measured in "inch-pounds" per minute. In the text the author speaks of tons or lbs. per sq. inch (not ton weights etc.), and his attitude towards " $g$ " when he has to use it is apt to be reserved (see Art. 72). Our own view is that so long as it is sufficiently clear what is meant, the terminology employed in referring to the unit of stress is of secondary importance. So long as "factors of safety" are as elastic (in the usual sense) as at present, it does not much matter whether the standard ton resides in London or New York.

This review has been written under the belief that what the readers of the BuLleTIN are accustomed to is a critical examination of books, and not the kind of general appreciation that is so easy to write and so pleasant (for the author's uncritical friends) to read. Lest, however, the Bulletin may occasionally fall into the hands of uncritical persons, it may be well to state explicitly that in many respects Professor Ewing's book is an excellent one, especially as an introduction to the subject. In general, it is clearly written and well arranged, and bears evidence of the author's ex- 
perience as a teacher. My criticisms largely arise from the fact that the author seldom indicates the limitations and uncertainties in the mathematical methods adopted, or supplies references whence his readers might obtain the knowledge which the book does not itself supply. Even in the parts of the work dealing with experimental results one is rather struck by the paucity of references to recent work done outside the author's laboratory. The insertion of long lists of authorities in an elementary book may savor of ostentation, but the author goes too far in the opposite direction.

The book seems carefully printed. Of the few errata I have noticed the following are the chief not already referred to :-p. 84, 1.19, for " then" read "there"; p. 101, last line, for "negative" read "positive"; p. 108, lines 22 and 23, interchange " upper" and "lower" (?); p. 111, 1. 6 from foot, insert "greatest" before "stress"; p. 117, case 4, the force $F_{x}$ increases uniformly (algebraically) from one end to the other ; p. 126, the conclusion that shearing stress is greatest at the neutral axis would follow from proof given only if breadth $\zeta$ constant; p. 135, in lines 9 and 10 of Art. 102, interchange "above" and "below"; p. 158, 1. 2 below fig. 101 , for 188 read 116 ; p. $185,1.3$ from foot, for " $M$ "' read " $M_{1}$ "; p. 207, " $t$ " is omitted in denominators of formulæ for $f$ and $f^{\prime}$ in Art. 142 ; p. 208, " $\theta$ " should be shown in Fig. $136 ;$ p. 227,1 . 10, for $d M / d a$ read $d M_{p} / d a$.

RICHMOND, SURREY,

Charles Chree.

July 2, 1900.

\section{SCHEFFERS' DIFFERENTIAL GEOMETRY.}

Anwendung der Differential- und Integralrechnung auf Geometrie. By Dr. Georg Scheffers, Professor in the Darmstadt Polytechnic School. Erster Band: Einführung in die Theorie der Curven in der Ebene und im Raum. Leipzig, Veit and Co., 1901.

THE author of this work has already proved his capacity for writing text-books in a clear and readable manner, in the three volumes of Lie's works which he edited. The present volume is arranged and written in the same attractive and on the whole satisfactory style-for which the 